\title{
Academic Writing for Publication and English as a Lingua Franca Audiences
}

\author{
Kelly Kimura \\ Soka University, Tokyo, Japan
}

English as a Lingua Franca (ELF) has been described as "any use of English among speakers of different first languages for whom English is the communicative medium of choice, and often the only option" (Seidlhofer, 2011, p. 7). ELF is not used exclusively among non-native speakers; the "first languages" in this description include English (Jenkins, 2009; Seidlhofer, 2011). In spoken ELF interactions, when there are differences in language proficiency or difficulty in comprehension, speakers tend to cooperate to help the interaction succeed (Mauranen, 2012; Seidlhofer, 2011). The study of written ELF in academic settings (WrELFA) is an emerging field (see http://www.helsinki.fi/englanti/elfa/wrelfa); if and how ELF authors of academic papers write differently from native English speaking authors for the success of their interactions with audiences are not yet known. As non-native English-speaking teachers and other language education professionals find increasing acceptance in the field (see Yilin Sun's article in this issue), these audiences include growing numbers of ELF users. In the absence of studies on the topic, as an advocate for both our authors and our audience, I recommend that authors, regardless of their first language, consider how to successfully communicate with audiences which include ELF users.

That authors follow this recommendation is of obvious importance to this publication. Language Education in Asia (LEiA) has an international readership of multilingual language users and monolingual users of English. The journal's reach is even wider than the 26 countries from which we have received submissions in the past three years. Every year, CDs containing all issues to date are distributed to all CamTESOL Conference participants. At the $10^{\text {th }}$ annual conference earlier this year, participants came from over 40 countries. Furthermore, the publication is freely available online. Teachers, researchers, and other language education professionals in Cambodia, Vietnam, Myanmar, and Laos are part of the LEiA audience, as are those in Australia, Japan, and the U.S.

Authors interested in sharing their research and teaching practices must think of this audience when writing for submission to LEiA. Assuming that papers are based on good research projects (see Brian Paltridge's paper in this issue), there are several general items for authors to consider. First, authors should address the greater readership, not only narrow audiences within, such as other researchers interested in the same topic or university teachers in a certain country. This means that authors need to study what is happening beyond their own contexts in the region and include this information in their papers. Authors should also consider the audience's familiarity

Language Education in Asia, 2014, 5(1), 1-6. http://dx.doi.org/10.5746/LEiA/14/V5/I1/A01/Kimura 
with the topic, relevant areas of the topic where the audience lacks knowledge, and what its members would like to know about the topic. Next, authors should realize that teachers as well as researchers may read their research articles; teachers may look for recommendations that can improve their related practices. Authors of teaching practice papers should provide information on practices and materials that can be adapted for use in different situations. In addition, authors must consider the diverse audience contexts throughout Asia.

However, the considerations above are not sufficient for an audience that includes ELF users. While we at LEiA expect submissions to be professional and academic, academic writing should not hinder communication with our audience. In papers where reading academic writing is difficult for native speakers of English in academia (Pinker, 2014), highly proficient ELF users will have at least the same difficulties. Access to current knowledge in the field is already limited in some of the areas we serve. When up-to-date papers are available, they do not benefit the audience if the authors have used academic writing for purposes other than communicating. When an author does not focus on appropriately communicating with the audience, academic prose can easily get in the way of the message.

Authors should acknowledge that users of ELF form the majority of our audience by writing papers for submission to LEiA using academic English as a lingua franca. Here, writing with a lingua franca perspective means that authors make accommodations to help their attempt to communicate succeed with ELF audiences. While in an ELF conversation, participants can negotiate meaning as communication breakdowns happen (Mauranen, 2012; Seidlhofer, 2011), readers are likely to decipher texts for meaning alone. When readers have difficulties with a paper, they may use a dictionary or ask someone for help; however, they may also stop reading. If an author's goals are to contribute to knowledge in language education, engage the interest of the audience, and encourage further research, discussion, or improved practice-that is, if the author wants to communicate with our audience-the author should accommodate the audience from the beginning to try to avoid communication breakdowns. These accommodations include being clear and concise, yet sufficiently explicit.

Writing with clarity will more effectively communicate the author's message to ELF users. Papers too often include passages where meaning (or lack of meaning) is obscured by the use of the passive voice, overly complex sentence constructions, jargon, and more. Writing should present the content, not itself. While not aimed at writing for ELF audiences, a relevant and thoughtprovoking article on academic writing for publication and an accompanying free, downloadable booklet point out problem areas and give guidance on writing more clearly (Pinker, 2014).

Writing with conciseness also conveys the author's message more effectively to ELF audiences. We regularly see oversized submissions above and below our word limits, but authors should not burden audiences of ELF users with redundant text. Regardless of the article's length, words, sentences, and passages should be examined objectively and eliminated when they are unnecessary. Authors struggling with being concise sometimes declare that reducing any part of the paper is impossible; however, what usually emerges is a better text. Authors should note that article word limits are the maximum number of words allowed, not the number of words required. If complete, clear, and concise, an article with a word count lower than the word limit will not suffer in the review process for this reason. It will also be much appreciated by an audience which traditionally has little free time. 
While clarity and conciseness are important accommodations, at the same time, writing with explicitness is necessary for this varied ELF audience. Sufficiently explaining terms, procedures, and other items is essential. We have noticed that sometimes a deep knowledge of the topic leads an author to forget that the audience does not share this familiarity. Our editorial team and review editors form a first, constructively critical audience to represent our larger audience, and we often ask for more explanations and details. Authors should check that their articles are sufficiently explicit, perhaps by asking other people to read their work. If the paper is not explicit enough, the audience's work in understanding is more difficult than necessary.

Although having a paper published is an accomplishment, a truer mark of scholarship is an author's ability to present relevant research and practices in an accessible way and thus inspire and inform further research, action, and discussion by the audience. This ability starts with considering the audience. While all of the accommodations above could and should be done for writing in general, for this publication and many others, authors must be more conscious of making accommodations when writing for audiences of ELF users.

As Mauranen (2012) noted regarding speakers of academic English, there are no native writers of academic English. The increasing interactions between authors and ELF readers have the potential to improve academic writing. By taking the lead in consciously using English as a lingua franca to communicate with ELF audiences, authors of all language backgrounds can contribute to making reading and learning for research and professional development more audience-friendly for this community of communities.

Turning to the papers, Volume 5, Issue 1 starts with an article by Yilin Sun, LEiA Advisory Board member, opening plenary speaker at the $10^{\text {th }}$ CamTESOL Conference, and current President of TESOL International. She writes on important worldwide trends that she observes in these areas in the language education field: perspectives on the field, educational goals, teaching approaches, curriculum content and design, communicative competence, non-native English speaking teachers (NNESTs) as English language educators, the timing of the introduction of English as a foreign language in educational systems, information technology, and the roles and responsibilities of teachers. The influence of NNESTs on a number of these trends is shown.

Brian Paltridge, the current co-editor of TESOL Quarterly and author or editor of publications on academic writing, research methods, discourse analysis, and English for Specific Purposes, was a plenary speaker for the CamTESOL Regional Research Symposium. While his plenary topic was "Current and Future Directions of English for Specific Purposes Research," his paper in this issue is on his CamTESOL workshop topic: "What is a Good Research Project?" This article is particularly excellent for beginning researchers and those who need guidance or a review. Brian covers developing research questions and proposals that lead to well-constructed research projects and papers with a good potential for publication. He discusses an interesting study to illustrate the characteristics of a good research project and lists resources for further guidance.

The research section begins with Do Thi Quy Thu and Dang Thi Cam Tu's study on video recording presentations for use as feedback in a public speaking course at a university in Vietnam. Students' ability to observe and reflect on their own performances had positive effects on their communication competence and apprehension about public speaking. In the second research paper, Indika Liyanage and Brendan Bartlett in Australia and Thomas Tao in China report on the 
extent of Chinese university students' usage of the cognitive strategies of translation, deduction, and contextualisation when listening and speaking in EFL classes. The authors discuss the need to develop students' oral communication skills and the washback of China's required English test for university graduation on EFL programs. In the next paper, Kerry Pusey and Karen Lenz examine the relationship between visual input, working memory, and L2 listening comprehension, particularly in the context of assessment. They provide questions for teachers to consider to more effectively assess L2 listening with visual input. From Japan, James Emmet Owens describes an experiment at a university in which students used a standard reading exercise (SRE) in a foundational literacies course. The SRE, used repeatedly throughout the term with a range of texts, is found to have a number of benefits. The SRE is included in the appendix.

How Japanese university students feel about peer feedback for written work and how teachers think students feel are explored by Brett Morgan, Bjorn Fuisting, and Jeremy White. They offer useful suggestions for teachers interested in using peer review. Linda Mary Hanington reports on a study on professional development in the area of reading aloud for preservice primary school teachers in Singapore. The phonological awareness that teachers gained from an intensive program may improve their required reading aloud activities in the classroom. In the final research paper, from Japan, Michael Guest reports on his field observations of conference presentations and the speech forms used in four areas of successful performances. While the professionals he observed were in the medical field, the examples are suitable for professionals in many other fields.

The teaching practice section starts with Monica Hamciuc's examination of Japanese students' perceptions of the effect that studying with international students had on their communicative skills and confidence. In their shared classes, Japanese students prepared topics of their choice for discussion or presentation and had opportunities to ask and answer questions. From Indonesia, Ignatius Harjanto writes about teaching academic writing to graduate students using the I-Search approach, in which students choose, research, and write about a topic that has interest and meaning for them. On a post-course questionnaire, students indicated the approach had been useful in developing their writing skills. In the last paper in this section, Aeric Wong and Paul Leeming, writing from Japan, demonstrate that dictation can be used as an informal and inexpensive test of language proficiency. The authors use dictation tests for purposes such as group construction in classes with students of varying language proficiency levels. The design and administration of such a dictation test is described.

The issue concludes with the first book review for LEiA, co-authored by George M. Jacobs in Singapore and Harumi Kimura in Japan. The topic of Graham V. Crookes' Critical ELT in Action: Foundations, Promises, and Praxis, incorporating social justice into second language education, is one of the trends Yilin Sun observes in her plenary paper. The reviewers examine a number of points Crookes explores and show that Crookes' deft handling makes responsible critical pedagogy accessible for teachers who are interested in its practice for their classrooms.

Moving on to the people behind LEiA, many people contribute a generous amount of time and effort to LEiA and the production of each issue. I am very grateful to John Middlecamp for his continuing work for the journal. John created the framework of our new editorial team and has also authored or made major contributions to documents that are making the publication process run more smoothly. In addition, he is in charge of copy editing. Our new editorial team members include Keuk Chan Narith, a longtime review editor who has received recognition from the 
CamTESOL Conference for his contributions to scholarly research on education in Cambodia. Rith now oversees the initial screening of papers and is additionally is responsible for the review and revision process for Issue 2. Rith recently gave a presentation titled "English Language Teacher Research in Cambodia: Development and Challenges" at AILA (International Applied Linguistics Association) in Australia. Another new editorial team member, Naashia Mohamed, has joined us from the Maldives; she is in charge of the review and revision process for Issue 1 of each volume. She also presented at AILA; her presentation was titled "Bilingual Children's Language Use and Linguistic Identity: Home Contributions and Family Language Policy." Rheanne Anderson, Caroline Ho, and Anthony Fenton coordinated reviews and revisions between authors and review editors and checked papers at every step for Issue 1; Rheanne and Caroline continue to do so for the second issue. Alice Svendson and Deborah Sin ably assist John Middlecamp in copy editing. I very much appreciate the editorial team members' voluntary work for LEiA on top of their responsibilities at their universities or institutions and elsewhere. My thanks and best wishes go to Phanith Pheng, who was our very capable editorial assistant; he is leaving us to further his education. We welcome our new assistant, Vathana Serey.

The editorial team relies on our dedicated Editorial Board to inform our decisions on papers and guide authors in revising. Their professionalism and their willingness to support the journal and their peers in contributing to published knowledge in the field are essential for LEiA, and we are grateful. Gratitude also goes to the Advisory Board for their continued valuable guidance and support.

Thank you to all the authors who submitted for consideration for publication. There were many good papers, and we had difficult choices to make.

Finally, congratulations to those whose articles appear in this issue. We appreciated these authors' patience with our questions and our requests; they were made with our audience in mind. 


\section{Editor's Note}

\section{References}

Jenkins, J. (2009). English as a lingua franca: Interpretations and attitudes. World Englishes, 28(2), 200-207. http://dx.doi.org/10.1111/j.1467-971X.2009.01582.x

Klimpfinger, T. (2007). 'Mind you, sometimes you have to mix' - The role of code-switching in English as a lingua franca. Views, 16(2), 36-61. Retrieved from https://anglistik.univie.ac.at/fileadmin/user_upload/dep_anglist/weitere_Uploads/Views/Vie ws_0702.pdf

Mauranen, A. (2012). Exploring ELF: Academic English shaped by non-native speakers. Cambridge, U.K.: Cambridge University Press.

Pinker, S. (2014, September 26). Why academics stink at writing. The Chronicle of Higher Education. Retrieved from http://chronicle.com/article/Why-Academics-WritingStinks/148989/

Seidlhofer, B. (2011). Understanding English as a lingua franca. Oxford, U.K.: Oxford University Press. 